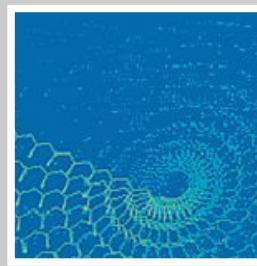

\title{
Polymer and Colloid Highlights
}

\section{Division of Polymers, Colloids and Interiaces}

A Division of the Swiss Chemical Society

\section{Anionic Vesicles Can Control the Reaction Pathway of a Highly Reactive Intermediate}

\section{Sandra Luginbühl and Peter Walde*}

${ }^{*}$ Correspondence: Prof. P. Walde, Department of Materials, ETH Zürich E-mail: peter.walde@mat.ethz.ch

Keywords: Dispersed interfaces - Enzymatic oxidation · Polyaniline $\cdot$ Reaction pathway control $\cdot$ Vesicles

The presence of anionic vesicles from sodium bis(2-ethylhexyl)sulfosuccinate (AOT) during the enzymatic oxidation of the aniline dimer, $p$-aminodiphenylamine (PADPA), leads to the formation of oligomeric products which resemble polyaniline (PANI) in its protonated, half-oxidized, half-reduced emeraldine salt form (PANI-ES). [1] These green, redox-active products are characterized by a high radical content and a high absorption in the near infrared (NIR). In the absence of vesicles but otherwise identical conditions, completely different products are formed: they are purple in color with a low radical content, are redox inactive, and precipitate (Fig. 1).

In order to gain a molecular and mechanistic understanding of the observed phenomenon, we conducted an in-depth study of the reaction of Trametes versicolor laccase (TvL) with PADPA at $\mathrm{pH}=3.5$ both in the presence and absence of AOT vesicles. ${ }^{[2,3]}$ In situ measurements using UV-vis-NIR-, EPR-, and Raman

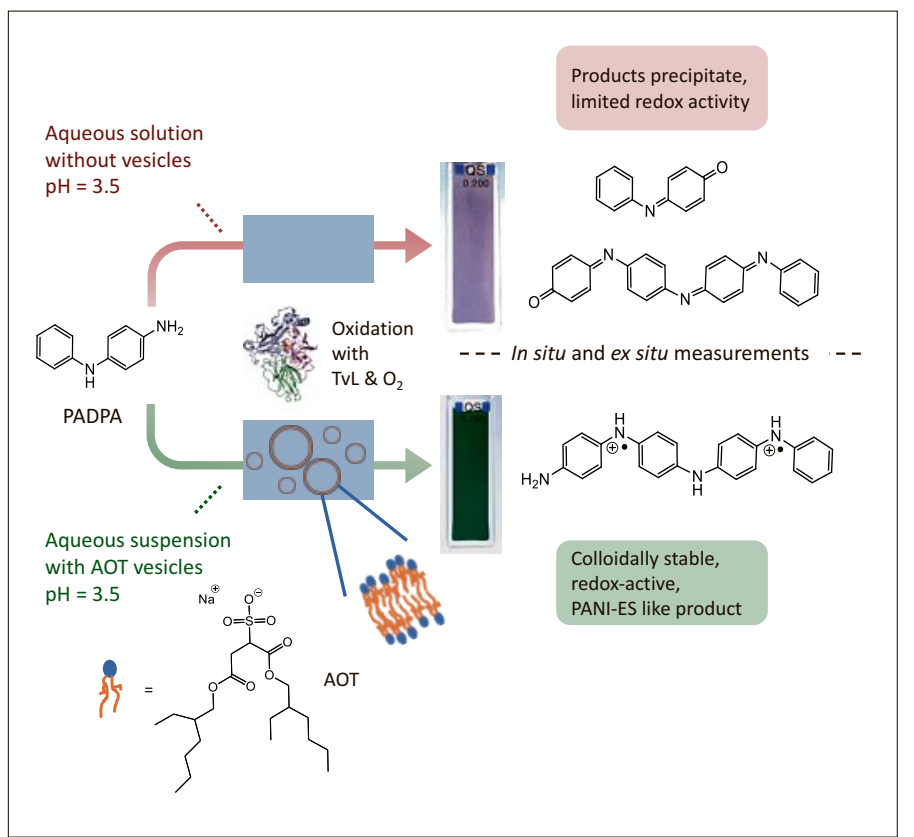

spectroscopy were combined with ex situ HPLC-MS measurements of the reaction products formed from selectively deuterated PADPA. It was determined that with vesicles, the linear, $\mathrm{N}-\mathrm{C}$-para coupled aniline tetramer with polaron centers $\left(-\mathrm{NH}^{\cdot+}-\right)$ is primarily formed. ${ }^{[2]}$ Without vesicles, PADPA, as well as the aniline tetramer, undergo hydrolysis and further degradation reactions. Molecular dynamics simulations showed that PADPA and its highly reactive intermediate oxidation product ( $N$-phenyl1,4-benzoquinonediimine, PQD) are both embedded within the AOT vesicle membrane. ${ }^{[2,4]}$

PQD can react in different ways under acidic conditions: it can react with $\mathrm{H}_{2} \mathrm{O}$ to form hydrolysis products; and it can undergo para and ortho coupling with another PQD molecule to form PANI-type oligomers which themselves can be either protonated or deprotonated, with varying degrees of oxidation. The AOT vesicles, which contain a hydrophobic domain as well as a high density of negative charges at the bilayer surface and thus have a completely different microenvironment than bulk water, can control the reactivity of PQD by suppressing hydrolysis and favoring the coupling reactions (mainly para). In addition, the vesicles also stabilize the final, desired product in two ways: the AOT vesicle membrane acts as a co-solvent to ensure colloidal stability, and the negative surface charge acts as a counter ion to the cationic PANI-ES type oligomer.

These results lead to the generalized finding that AOT vesicles can be seen as dispersed, soft vesicular interfaces which exert 'reaction pathway control' in aqueous solutions. The concept of reaction pathway control may be applicable to other organic reactions using different types of vesicles or micelles ${ }^{[5]}$ in water, especially in the field of synthetic green chemistry. ${ }^{[6]}$

\section{Acknowledgments}

SNF (Project 200020_150254) and SCOPES Joint Research (Project IZ73Z0_152457).

Received: May 242017

[1] K. Junker, S. Luginbühl, M. Schüttel, L. Bertschi, R. Kissner, L. D. Schuler, B. Rakvin, P. Walde, ACS Catal. 2014, 4, 3421.

[2] S. Luginbühl, L. Bertschi, M. Willeke, L. D. Schuler, P. Walde, Langmuir 2016, 32, 9765

[3] A. Janoševic Ležaić, S. Luginbühl, D. Bajuk-Bogdanović, I. Pašti, R. Kissner, B. Rakvin, P. Walde, G. Ćirić-Marjanović, Sci. Rep. 2016, 6, 30724.

[4] MD simulations by Dr. Lukas D. Schuler, xirrus GmbH, xirrus.ch

[5] B. Lipshutz, J. Org. Chem. 2017, 82, 2806.

[6] F. Gallou, N. A. Isley, A. Ganic, U. Onken, M. Parmentier, Green Chem. 2016, $18,14$.

Fig. 1. Change in product distribution if PADPA is oxidized with Trametes versicolor laccase (TVL) in the absence (top) or in the presence (bottom) of anionic AOT vesicles. 